Synthesis, vol. $25 \mathrm{n}^{\circ}$ 1, e035, junio 2018. ISSN 1851-779X

Universidad Nacional de La Plata.

Facultad de Humanidades y Ciencias de la Educación.

Synthesis

Centro de Estudios Helénicos

\title{
Fábio de Souza Lessa. Atletas na Grécia Antiga. Da competição à excelência, Mauad X, Río de Janeiro, 2017, 165 pp.
}

\section{Graciela C. Zecchin de Fasano* \\ * Universidad Nacional de La Plata, Argentina}

Cita sugerida: Zecchin de Fasano, G. C.(2018). [Revisión del libro Atletas na Grécia Antiga. Da competição à excelência por Fábio de Souza Lessa]. Synthesis, 25(1), e035. https://doi.org/10.24215/1851779Xe035 
Fábio de Souza Lessa. Atletas na Grécia Antiga. Da competição à excelência, Mauad X, Río de Janeiro, 2017, 165 pp.

Graciela C. Zecchin de Fasano

Universidad Nacional de La Plata, Argentina

El estudio del deporte como herramienta de cohesión social y del papel del atleta como un "héroe" ciudadano ha sido objeto de las investigaciones de Fabio de Souza Lessa desde hace muchos años. Su experiencia en este tema lo ha llevado a ofrecernos en el presente volumen un abordaje enriquecido por la múltiple utilización de testimonios literarios y plásticos, en un itinerario que comprende desde el período arcaico hasta el período clásico. Basándose en que el deporte fue -junto con el teatro y el ágora- un espacio privilegiado de discusión dentro de la pólis, el libro procura un análisis de la vinculación entre el proceso de adquisición de excelencia o areté del ciudadano-atleta con el imaginario mítico y con las prácticas religiosas.

En la "Introducción", el autor provee una definición del concepto de deporte para el mundo contemporáneo extraída de Rial (1998), para señalar inmediatamente que el mismo concepto resulta definido entre los griegos antiguos a través de las palabras agón, áthlos y gymnásion. La pervivencia de las prácticas deportivas a lo largo de la historia revela que en el mundo griego ellas estuvieron marcadas por un fuerte sentido ritual e icónico, un hecho que justifica claramente la exclusión de los extranjeros de los juegos helénicos. De este modo, de Souza Lessa sostiene que los juegos colaboraron en la construcción de un discurso sobre la diferencia. Una diferencia que no solo era relativa a los griegos y los extranjeros, sino que también se construía en el interior de la pólis, ya que otorgaba posiciones de privilegio y generaba un discurso de exclusión en torno a los juegos y sus modalidades.

El libro aporta cuadros muy claros con la síntesis de las fuentes utilizadas, que de Souza Lessa ha ordenado y evaluado sin dejar de lado las de carácter literario, a las que ha puesto en valor en conjunto con las imágenes de vasos griegos que pondera con un adecuado equilibrio. Dichas imágenes aportan la mayor cantidad de escenas deportivas en el escenario de la vida cotidiana y, en su carácter de productos elaborados dentro de un sistema cultural, deben ser comprendidas como índices de realidades y códigos de conducta de esa sociedad.

En el capítulo 1, "Excelência e inmortalidade: vencer nos Jogos Helênicos", el autor aborda fundamentalmente la relación entre el proceso por el cual se adquiere areté, el imaginario mítico y las prácticas religiosas, visibles en el grupo social de los kaloi kagathoi en período clásico. Para ello parte de la definición de atleta como héroe, en un sentido completamente diferente del acuñado en la poesía épica. El atleta, un héroe democrático, adquiría inmortalidad en la memoria colectiva sin ser un semidiós. La forma en que el período clásico absorbió un código antiguo es estudiada por de Souza Lessa a partir del célebre e inevitable episodio de los juegos funerales en honor de Patroclo en Iliada XXIII.257-897 y del festival feacio en Odisea 8.100-223. Cada apartado se centra en aspectos esenciales, como el significado de los juegos y la excelencia en la victoria, los juegos como factor de identidad política, los juegos como experiencia ritualizada, el valor de los premios -ya sean simbólicos o materiales- y las imágenes de atletas en la cultura material. El proceso ritual resulta fundamental, ya que los cuatro juegos panhelénicos tenían su base en la religión y en una supuesta fundación mítica, y era esta concepción la que habilitaba la heroización del atleta y su inmortalización en la memoria políade. Para de Souza Lessa todo acto cívico adquiere en la pólis una dimensión religiosa y la religión es uno de los elementos insoslayables de la identidad de los helenos. Esto resulta claramente expuesto en cuadros que sintetizan la vinculación entre juegos, religión y sacralidad de los vegetales usados en la premiación. Basado en el concepto de identidad relacional de Augé, de Souza Lessa propone la Olimpica I de Píndaro (vv. 66-89) como ejemplo del lazo estricto entre religión, juegos y vida política. La sustentación en la cultura material lo lleva a reconocer que en la imagética deben 
contemplarse tanto la cuestión de la circulación de sus mensajes como la construcción de sus narrativas, que son sincrónicas y exhiben todo simultáneamente, frente al texto escrito que narra necesariamente en forma diacrónica. Concluye el autor que los juegos refieren a dos procesos instituidos formalmente en el siglo VIII a. C.: la fundación de una nueva forma de vida en sociedad, representada por la pólis, y el proceso de colonización del Mediterráneo, es decir que los festivales atléticos reforzaban por un lado el ideal políade; pero, por otro lado, lo extrapolaban.

El Capítulo 2 "Os Jogos aristocráticos: as modalidades hípicas" se ocupa fundamentalmente de un análisis de los espacios y competiciones hípicas apartir del modelo desarrollado por los juegos en honor a Patroclo y cómo esa versión épica fue "leída" por los pintores de vasos, con el fin de exponer como aspectos temáticos esenciales la velocidad y la belleza presentadas como cualidades de los agônes en el hipódromo, tanto en corridas de carros como de caballos. El epígrafe de este capítulo expone con claridad que las prácticas deportivas con caballos correspondían a una élite económica y que ese rasgo se ha proyectado desde el mundo antiguo hasta la actualidad. También destaca el autor que el caballo, en asociación con Poseidón, ha pasado de la poesía épica a la tragedia. Son notables las citas de Ifigenia en Táuride o de Hipólito de Eurípides para demostrar este argumento. En el cuadro de la página 58 se ejemplifica la afirmación de la práctica hípica como ostentación de riqueza y poder a partir de textos de la comedia aristofánica y de Jenofonte. El plano del hipódromo de Olimpia, según las conclusiones del equipo de arqueología e historia de la Universidad de Mainz, constituye otro de los aportes sustantivos para la comprensión de estas prácticas, que de Souza Lessa incluye acertadamente.

No menos atractiva resulta la comparación que se realiza entre los funerales de Patroclo y los de Héctor en Ilíada. Apoyado en las observaciones de Schnapp-Gourbeillon, el autor señala que las diferencias culturales entre aqueos y troyanos surgen sobre el final del episodio funeral, ya que entre los troyanos se cierra con el banquete fúnebre y entre los aqueos se cierra con los juegos. El ritual fúnebre coloca a Patroclo entre la muerte y la inmortalidad, es decir, finaliza su construcción como héroe. El análisis de la lectura de estos episodios en la cerámica le permite a de Souza Lessa trazar comparaciones estrictas entre texto e imagen, e incluso vincular la carrera de carros con el episodio de la muerte de Orestes en Electra de Sófocles (vv. 718 y ss.) y con los episodios hípicos de las Olímpicas I y II de Píndaro. Nuevamente la conclusión extraída de la comparación entre texto e imagen es que la imagen conlleva un encuadre espacio-temporal diferente. En esta ocasión se analizan una cratera (nro. 4209, Museo Arqueológico Nacional, Florencia) y un ánfora panatenaica (56.171.4, Metropolitan Museum of Art, New York), entre otras. Aunque el estudio de las Grandes Panateneas no es objeto del libro, de Souza Lessa se sirve de un número interesante de ánforas de este tipo para colocarlas en diálogo con obras de Jenofonte como Sobre la Caballería o Hipárquico. El corpus de vasos analizado demuestra que pintores y poetas valorizaban una práctica aristocrática que era consumida por un público muy numeroso en período arcaico.

En el Capítulo 3 "Os Jogos democráticos: as modalidades 'atléticas", estudia especialmente la belleza masculina como parámetro estético, evaluado en relación con la exposición de la desnudez en gimnasios y palestras. Cada área del cuerpo desarrollada por entrenamiento se prueba en una disciplina, así los pies veloces en las carreras a pie, los brazos y piernas hábiles en el lanzamiento del disco, del dardo y en el salto. No faltan los deportes de contacto como la lucha, el boxeo y el pancracio, ni los juegos que requieren movilidad, como el pentatlón. De Souza Lessa propone acertadamente que el cuerpo del atleta constituye una sublimación del cuerpo cívico y que, particularmente, el discóbolo resulta un ícono de la democracia.

Cobra notable relevancia la clara distinción entre el hipismo, como una modalidad deportiva aristocrática, y el atletismo, como el desarrollo de habilidades corporales que expresan una visión democrática. Al no exigir un equipamiento costoso, esta última práctica distribuía ese estilo aristocrático sobre los ciudadanos menos provistos. De Souza Lessa se sirve de citas de Odisea 8.145-148, de fragmentos de Cármides de Platón sobre la belleza y desnudez apolínea del cuerpo masculino y luego se apoya en textos de Heródoto, en que la desnudez griega se opone a la barbarie vestida de los persas (VII. 61-82). Como la desnudez asocia atletas, 
héroes y dioses, el capítulo se construye sobre el comentario de un corpus de 13 vasos y 15 imágenes sobre la base de criterios ya desarrollados por de Souza Lessa con anterioridad, a saber, que los cuerpos de los atletas representados en los vasos siguen un patrón geométrico de idealización y que esa representación ofrece un patrón hegemónico de masculinidad.

Algunos vasos demuestran la existencia de un mercado en Etruria y otros colocan una pluralidad de cuerpos que tratan de retratar las diferencias sociales, de manera que las cuestiones de consumo se adjuntan a la información de corte social. Otro aspecto interesante lo constituye el espacio de entrenamiento, que aparece en los vasos como un espacio social modificado. De Souza Lessa distingue entre gimnasio y palestra como sedes de ejercitación, para abordar luego el estadio, sede de las carreras pedestres. El estadio remitía, naturalmente, al mito de Heracles, pero también a la firmeza con que se ubicaba el atleta en la línea de partida.

Ciertos testimonios de Filóstrato pondrían en duda si un mismo atleta cumplía con el lanzamiento del disco, del dardo y con el salto. En todo caso, el patrón recurrente en los vasos analizados es contar con la inscripción kalós, con lo cual los atletas retratados son insertados en el grupo de los kaloika gathoí.

En el caso de los llamados deportes de contacto, como la lucha, el boxeo y el pancracio, partiendo de testimonios de Baquílides y Filóstrato, de Souza Lessa explica que el pancracio era la prueba más violenta de los juegos, de la que pueden hallarse antecedentes en la confrontación entre Epeo y Euríalo en Ilíada XXIII. 685-699. En particular, el análisis de la cara B del vaso inventariado como 1972.44 en el Museum of Fine Arts de Boston, permite ver que se preferían los golpes en la cabeza de los adversarios, porque se trataba de golpes muy efectivos. Estas modalidades implicaban movimientos por separado de distintas partes del cuerpo que servían para introducir la práctica más completa, el pentatlón. Al implicar movimientos de todo el cuerpo, requería de los atletas más completos y es considerado el primer evento múltiple de la historia del atletismo. La determinación del vencedor se basaba en las tres primeras pruebas. En cada caso, de Souza Lessa se sirve de testimonios de la Retórica de Aristóteles, Suplicantes de Esquilo y Caballeros de Aristófanes para demostrar que las modalidades no hípicas tenían de igual modo un perfil aristocrático y excluyente.

Finalmente, de Souza Lessa contrapone estas modalidades a la que considera la más democrática: el lanzamiento del disco, para equiparar el cuerpo del atleta al cuerpo cívico. Analiza fundamentalmente esta práctica como símbolo de la democracia ateniense por estar abierta a los distintos segmentos sociales y por requerir equipamiento más accesible. Tres figuras sirven de soporte a su análisis, el vaso inventariado bajo el número 111 del Museo del Louvre, la kýlix inv. P2698 del Museo del Ágora y el ánfora panatenaica inv. P86357 del Museo Arqueológico de Nápoles. Resulta interesante cómo el autor asocia el esquema circular del movimiento del discóbolo con las estructuras circulares o semicirculares como la pnixx, que permitían un desnudamiento o develamiento metafórico del ciudadano.

La conclusión general del libro recurre nuevamente a pasajes de Ifigenia en Aulis y de Hipólito de Eurípides para destacar la relevancia del juego y de la competencia en la constitución del ideario democrático. Por una parte, porque la ficción trágica permitía lo imposible en términos de realidad histórica -por ejemplo, que Aquiles le ganara a la cuadriga de Eumelo-; por otra parte, porque los agônes deportivos eran espacios de predominio masculino, de exposición pública de los ciudadanos.

El libro se acompaña de cuadros muy didácticos y de un análisis selectivo, perspicaz y minucioso de un corpus de imágenes de vasos de distinta antigüedad con una sensata ponderación de la información históricosocial contenida en ellos y de las inferencias adecuadas que pudieran derivarse.

Por todo ello, Atletas na Grécia Antiga ofrece tanto a expertos como a estudiosos en general, una información precisa y valiosa, vertida con extrema claridad, sobre los juegos tal como fueron leídos en el arte y en la poesía. 